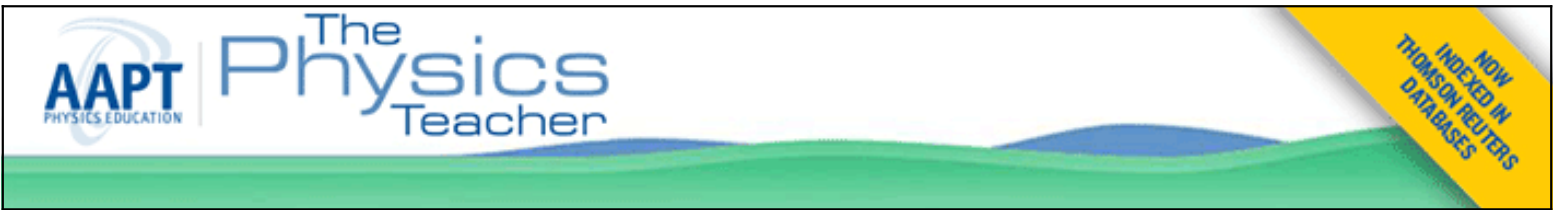

\title{
Encouraging Student Participation in Large Astronomy Courses
}

Shannon D. Willoughby

Citation: The Physics Teacher 50, 146 (2012); doi: 10.1119/1.3685109

View online: http://dx.doi.org/10.1119/1.3685109

View Table of Contents: http://scitation.aip.org/content/aapt/journal/tpt/50/3?ver=pdfcov

Published by the American Association of Physics Teachers

\section{Articles you may be interested in}

A Course Connecting Astronomy to Art, History, and Literature

Phys. Teach. 53, 396 (2015); 10.1119/1.4931004

Getting the Swing of Surface Gravity

Phys. Teach. 50, 232 (2012); 10.1119/1.3694077

How Can "Weightless" Astronauts be Weighed?

Phys. Teach. 50, 12 (2012); 10.1119/1.3670074

Physics Myth Busting: A Lab-Centered Course for Non-Science Students

Phys. Teach. 49, 448 (2011); 10.1119/1.3639159

A short course on observational astronomy

Phys. Teach. 37, 530 (1999); 10.1119/1.880394

\section{Collect Clean, Repeatable,} and Noise-Resistant

\section{Motion Data}

Vernier Dynamics Cart and Track

System with Motion Encoder

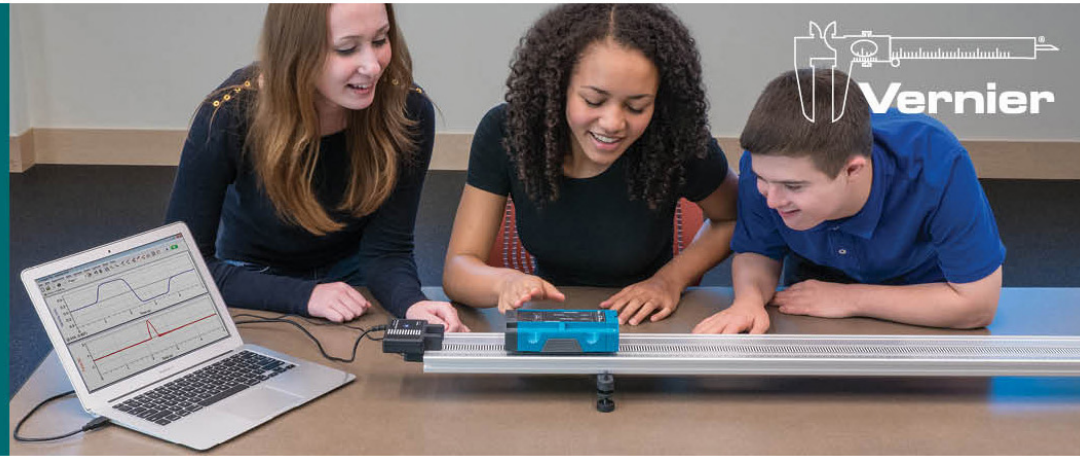




\title{
Encouraging Student Participation in Large Astronomy Courses
}

\author{
Shannon D. Willoughby, Montana State University, Bozeman, MT
}

$\mathrm{I}$ ntroductory astronomy is one of the most widely taught classes in the country ${ }^{1}$ and the majority of the students who take these classes are non-science majors. Because this demographic of students makes up the majority of astronomy enrollments, it is especially important as instructors that we do our best to make sure these students don't finish this course thinking that they can't do science, that only experts can understand scientific concepts, or that science is just an elaborate belief system. Ideally, at least some classroom time would be spent having the students use skills they already possess to explore concepts about astronomy. Realistically, we understand the time constraints and pressures felt by the average college instructor and the incredible amount of time and energy that can be required to rework a course.

Those of us familiar with Physics Education Research (PER) have seen (or read about) the incredible changes to student understanding that have taken place as a result of making those painful and time-consuming changes to physics courses. ${ }^{2}$ PER's younger sibling, Astronomy Education Research $^{3}$ (AER), aims to have the same sort of impact in the average astronomy course as well. Researchers in AER generally agree that the findings of the last couple of decades in PER hold in astronomy as well, specifically that the didactic straight lecture format is probably not the most effective approach to increasing student understanding. To that end, several innovative approaches have been put forth, including those of Zeilik et al., ${ }^{4,5}$ Hemenway et al., ${ }^{6}$ and Prather et al. ${ }^{7}$ Another innovation that has been successful in both physics and astronomy (as well as other disciplines) is the use of clickers. Judson and Sawada's ${ }^{8}$ recent review article nicely summarized many of the findings of clicker use in the classroom. But is there more we should be doing in astronomy? I have been using clickers in my astronomy and physics courses for several years, but it is also important to engage students in other ways also.

Rivard and Straw $^{9}$ found that both writing and talking about science can help students cement their understanding. Learning science is very much like learning a new language, not only because of the new vocabulary that must be mastered, but also because critical thinking takes practice, as does mastering the norms and culture of science. Fraknoi ${ }^{10}$ has compiled a list of astronomy-based poetry so instructors who wish to mix things up can introduce some poetry in class.

In order to get my students learning in a variety of ways, I have developed and adopted several activities for use in the astronomy classroom, only one of which needs any equipment at all, and all others can be implemented or adapted easily.
- In-class writing: Because I want students to understand that writing will be a regular part of the course, I have them write during the first class meeting. Although I change the question from time to time, the purpose of the exercise is to spark interest in the students, get them thinking, and most importantly to get them writing about science! Currently the question that I ask of them is to write down their favorite scientific invention (or discovery), why it is their favorite, and when it was invented (or discovered). I give them two minutes to write, keeping an eye on the clock and announcing when there are 30 seconds remaining. Also, while the students are writing, I write too. I do enjoy writing about this particular topic (I always choose something different to be my favorite), but, more importantly, this lets the students know that I take writing seriously.

After they have written for the allotted time, I ask them to share what they wrote with their neighbor(s) for another two minutes. The class immediately gets quite loud, and it can be challenging to bring their attention back, but again I warn them when they have 30 seconds left to complete the task. Once the class is quiet again, I ask students to volunteer to read what their neighbor has written. This helps the students feel less pressure, although many do volunteer to read their own statement. The responses vary wildly from the serious (electricity, fire, Kevlar) to the silly (birth control, beer, skis) to the odd (the A-bomb). Having students read to the whole class also helps set the tone for the semester, showing them that we will indeed have class-wide discussions where all 200 students are allowed and encouraged to participate.

- Haikus: Early in the semester I cover naked-eye astronomy so students can head straight outside and start watching and understanding objects in the night sky. After a lecture on various aspects of the Moon and its interactions with Earth (phases, eclipses, and tides), I show a slide defining a haiku for students who may not be familiar with this type of poem. (A haiku is a three-line poem in which the first and third lines consist of five syllables, and the second line has seven syllables.) Then I set them loose on the assignment: create three haikus about gravity, tides, and eclipses. How they interpret the directions varies from student to student, with some writing three haikus all containing the three subjects, some writing three haikus each containing one subject, and a few students coming up with their own topics. They share with their neighbors after the allotted writing time is up (typically about 10 minutes for this activity), then I ask for volunteers to read a neighbor's haiku to the class. The number of volunteers who read aloud is a function of the 
mood of the class, so sometimes we only hear five to six haikus, and occasionally we will hear 10 or 12 . One semester the whole class started snapping like beatniks after each of the haikus was read! Typically this is the only lecture during which I require students to write poetry, but it could certainly work with other topics as well.

- Be a slice of the Earth:11 During my lecture on Earth as a planet, I stress the idea that while we know a great deal about the Earth's crust, it really makes up a very small percentage of the overall volume of the Earth. In order to learn more about the interior of the planet, we must resort to indirect methods such as detecting waves created by earthquakes. To drive home the idea that the crust is only a small part of the whole planet, I have the students use one team member's body as a slice of the Earth. (Students are in learning teams consisting of four students each for the duration of the semester.) I give them values (in kilometers) of the depth of the Earth's crust, mantle, outer core, and inner core, and their task is to map this onto a human body where the top of the head is the Earth's surface and the bottom of their feet is the center of the inner core. Because these students tend to be quite math-phobic, I worried at first that this activity might not work (or that the students would not understand what was expected of them), but the activity worked out quite well. The groups that I listened to quickly realized that the easiest way to go about the problem was to convert all the distances to percentages, then map that to the body. After students had completed the project, I had all the student "models" come to the front of the classroom. While it was a tight fit to get all 50 students lined up at the front, they did a good job, and once lined up, I asked them all to point to their crust. The vast majority of students pointed at the top of their forehead, and I proceeded to ask them to point out their mantle and outer and inner cores. By the time we got to the more interior sections, there were discrepancies between the models, but students realized that and started looking at each other and adjusting. Finally, I ask the models to show how high above their heads the atmosphere should be, estimating that the height of the atmosphere is about $480 \mathrm{~km}$. All of the models were quite good sports and by the end of the show-and-tell pretty much the whole class was laughing out loud. Hopefully they learned something too!

- Kepler's third law experiment: ${ }^{12}$ Although students in astronomy typically have little or no experience thinking like scientists and performing experiments, this type of thinking is practiced regularly. Instead of just listing Kepler's laws (which becomes for the students merely a memorization task), I do an experiment in class and they must draw their own conclusions from it to glean Kepler's third law. The setup requires two balls with different mass (I use a tennis ball and a pool ball). A string is attached to each, and they are hung from a rod. I pull each back so that they exhibit simple harmonic motion, first with strings of equal 
length. The length of each string is changed, so that at one point the string is longer for the tennis ball, then longer for the pool ball. Despite the fact that this experiment involves simple harmonic motion and not full orbits, I tell them to imagine the apparatus making a full revolution around the fixed rod. Before I perform the experiment, a table is constructed on the board for students to copy down and enter both the expected and actual results of the experiments. I give them about two minutes to predict the outcome of each of the three experiments, asking them to decide which ball will swing the fastest in each case. Their task is to then conclude that the period of the motion is independent of the mass of the ball. This is followed up by a clicker question, asking what the length of a year would be on Jupiter if it were moved to the orbit of Mercury. (During the fall 2009 semester $86 \%$ of the students correctly surmised that the length of the year on Jupiter would now be equal to that of Mercury, and during the spring 2011 semester the students wrote down what conclusions they could draw about Kepler's third law from this experiment. Ninety-four percent of the students correctly surmised that the length of a planet's year is proportional to the size of its orbit, implying that the experimental setup was not hindering them in extrapolating the results from simple harmonic to orbital motion.)

Keeping students engaged in large lecture halls can be difficult, especially when the majority of the students are there mainly to fulfill a science requirement, so incorporating different activities makes the course more interesting both for the students and the instructor. Further, these activities are used in class primarily to shake things up and allow the students to approach the material from a different modality, so they are typically not graded for accuracy of astronomy content. (When they are graded it is simply for participation.) The haikus are occasionally collected so that I can better gauge student understanding. Their alternate conceptions are often reflected in the poems, and I get a snapshot of how the whole class is thinking about a particular topic. Many of these students tend to be afraid of science and math, so they enter the class feeling inferior (or sometimes superior) and often not terribly excited about astronomy. Each of these activities tends to create a more active learning environment where the students are encouraged to use skills they may already possess, and to get them really thinking about science in a way that is creative, productive, and fundamentally different than just passively listening to a lecture with the only active part of the course consisting of taking notes. Again, three out of the four activities require no special tools at all, nor do they take up a large portion of the class period. Go out and give these a try in your classroom!

\section{References}

1. A Fraknoi, "Enrollments in Astronomy 101 courses: An update," Astron. Educ. Rev. 1, 121-123 (2001).

2. R. R. Hake, "Interactive-engagement versus traditional methods: A six-thousand-student survey of mechanics test data for introductory physics course," Am. J. Phys. 66, 64-74 (Jan. 1998).

3. J. M. Bailey and T. Slater, "A review of astronomy education research," Astron. Educ. Rev. 2 (2), 20-45 (2003).

4. M. Zeilik, Interactive Lesson Guide for Astronomy, revised ed. (The Learning Zone, Santa Fe, NM, 1998).

5. M. Zeilik, C. Schau, N. Mattern, S. Hall, K. W. Teague, and W. J. Bisard, "Conceptual astronomy: A novel model for teaching postsecondary science courses," Am. J. Phys. 44, 987-996 (Oct. 1997).

6. M. K. Hemenway, W. J. Straits, R. R. Wilke, and B. Hufnagel, "Educational research in an introductory astronomy course," Innov. High. Educ. 26, 271-280 (2002).

7. E. Prather, T. Slater, J. Adams, and G. Brissenden, Lecture-Tutorials in Introductory Astronomy, 2nd ed. (Pearson, New Jersey, 2008).

8. E. Judson and D. Sawada, "Learning from past and present: Electronic response systems in college lecture halls," J. Comp. Math. Sci. Teach. 21(2), 167-181 (2002).

9. L. P. Rivard, and S. B. Straw, "The effect of talk and writing on learning science: An exploratory study," Sci. Educ. 84, 566-593 (2000).

10. Andrew Fraknoi, "Astronomy and poetry: A resource guide," Astron. Educ. Rev. 1, 114-116 (2002).

11. The activity "Be a slice of the Earth" was taken from T. Slater and J. Adams, Learner-Centered Astronomy Teaching: Strategies for Astro 101 (Pearson Education, New Jersey, 2003), p. 143.

12. Kepler's third law experiment was developed by Charles Kankelborg at MSU Bozeman.

Shannon Willoughby earned her PhD in physics in 2003 at Tulane University. She has been at Montana State University in Bozeman since 2005, teaching courses in physics and astronomy and doing research in the area of astronomy education.

Department of Physics, EPS 224, Montana State University, Bozeman, MT 59718; willoughby@physics.montana.edu 